\title{
Reescrituras de una misma geografía: Tensiones entre el Instituto Geográfico Militar (Buenos Aires), el Map of Hispanic America (Nueva York) y la Carte du Monde au Millionième (París - Londres) ${ }^{1}$
}

\author{
Carla Lois \\ Universidad Nacional de La Plata
}

\section{Resumen}

Este trabajo examina la red de debates, producciones y proyectos cartográficos nacionales organizados para satisfacer la voluntad de contar con un mapa del mundo basado en la cooperación internacional en nombre de la ciencia universal. En particular se analizan: los aportes de los enviados argentinos a los debates en las reuniones del Comité del Mapa del Mundo al Millonésimo (MMM o IWM); la organización institucional de las oficinas cartográficas en la naciente burocracia estatal argentina en relación con las demandas del IWM; la producción cartográfica de la Argentina para contribuir al proyecto; las "contestaciones" de las oficinas cartográficas argentinas a las hojas topográficas que la American Geographical Society había presentado como parte del plan provisional del Map of Hispanic America para suplir la falta de producciones locales.

Para indagar estas cuestiones sobre la base de materiales empíricos, se examinan cinco polémicas históricas: (1) el debate en torno a la confiabilidad de las fuentes y la obtención de datos; (2) las pugnas políticas planteadas en términos de dificultades metodológicas; (3) tensiones entre los objetivos internacionales y los intereses nacionales; (4) los conflictos geopolíticos en las islas del Atlántico Sur; y (5) las coincidencias y las disidencias entre los límites de las hojas y los límites políticos: economía gráfica versus “pureza geopolítica.” Este análisis mostrará que el territorio cartográfico ya se había vuelto un terreno tan disputado como el territorio geográfico.

Palabras claves: American Geographical Society, Mapa al Millonésimo, Map of Hispanic America, Instituto Geográfico Militar

\footnotetext{
Abstract

This paper examines the network of discussions, productions, and national cartographic projects organized to fulfill the need of having a map of the world based on international cooperation on behalf of universal science. Specifically, we analyze: the Argentinian participation at the meetings of the Committee of International World Map on the Journal of Latin American Geography, 14 (3), 2015 (C) Conference of Latin Americanist Geographers
} 
one-millionth scale (IWM or MMM); the institutional organization of the cartographic offices in the early Argentinian bureaucracy in relation to the demands of the IWM; the Argentinian cartographic production to contribute to the project; the "answers" of Argentine cartographic offices to the topographic sheets which the American Geographical Society had presented as part of the provisional plan of Map of Hispanic America to supplement the lack of local production.

In order to inquire into these issues on the basis of empirical materials, we discuss five historical controversies: (1) the debate about the reliability of sources and data collection; (2) political struggles presented in terms of methodological difficulties; (3) tensions between international goals and national interests; (4) geopolitical conflicts over the islands of the South Atlantic; and (5) similarities and differences between political boundaries and sheet borders: graphic economy versus "geopolitical purity." This analysis will show that cartographic territories had already become as disputed as geographical territories themselves.

Keywords: American Geographical Society, International World map, Map of Hispanic America, Instituto Geográfico Militar

"La frontera territorial, precisamente la más simple de las líneas, el trazo sin sombreado, tuvo que capitular ante la realidad."

"De fronteras, Razolike y otras cosas."

-- Karl Schlögel, En el espacio leemos el tiempo (2007: 141).

\section{Introducción: Dibujar mapas, construir geografías}

En 1908 se constituyó la Comisión del Mapa al Millonésimo en el Congreso Geográfico Internacional de Ginebra con el objetivo de coordinar la construcción de un mapa de la superficie terrestre con criterios comunes, y la Argentina adhirió a ese proyecto al año siguiente. A los efectos de legitimar y garantir su participación, la Argentina reorganizó las oficinas cartográficas existentes en ese entonces (en su amplia mayoría, de corte militar), y reorientó el programa de trabajo del recientemente creado Instituto Geográfico Militar (IGM) (1904) para suplir las veintiún hojas correspondientes al territorio argentino que completarían la Carte du Monde au Millionième.

Por esos años la American Geographical Society (AGS) se encargó del proyecto del Mapa de la América Hispánica para suplir las hojas sudamericanas al proyecto general de la Carte du Monde au Millionième. En el marco del Hispanic America Map, la AGS publicó, entre 1920 y 1945, 405 hojas topográficas 1: 1.000.000 correspondientes a América del Sur. Para ello recurrió a la recopilación de diversas fuentes y admitía la necesidad de usar materiales de dudosa precisión. ${ }^{2}$ La AGS, para evitar susceptibilidades con los gobiernos locales, publicaba sólo hojas "provisorias."

Si bien la Comisión Internacional del Mapa al Millonésimo (IWM, por sus siglas en inglés International World Map y MMM por sus siglas en español Mapa del Mundo 
al Millonésimo), la AGS y las instituciones cartográficas nacionales se proponían trabajar en colaboración y de manera mutuamente contributiva para armar un único mapa del mundo, lo cierto es que las prácticas y el trabajo de este "triángulo de instituciones" hizo emerger diferentes pugnas relativas a los modos de concebir las geografías de los estados nacionales y la representación de sus territorios.

Este trabajo examina la red de debates, producciones y proyectos cartográficos nacionales organizados para satisfacer la voluntad de contar con un mapa del mundo basado en la cooperación internacional en nombre de la ciencia universal. En particular se analizan: los aportes de los enviados argentinos a los debates en las reuniones del Comité; la organización institucional de las oficinas cartográficas en la naciente burocracia estatal argentina en relación con las demandas del IWM; la producción cartográfica de la Argentina para contribuir al proyecto; las "contestaciones" de las oficinas cartográficas argentinas a las hojas topográficas que la American Geographical Society había presentado como parte del plan provisional del Hispanic America Map para suplir la falta de producciones locales. Para indagar estas cuestiones sobre la base de materiales empíricos, se examinan cinco polémicas históricas: (1) el debate en torno a la confiabilidad de las fuentes y la obtención de datos; (2) las pugnas políticas planteadas en términos de dificultades metodológicas; (3) tensiones entre los objetivos internacionales y los intereses nacionales; (4) los conflictos geopolíticos en las islas del Atlántico Sur; y (5) las coincidencias y las disidencias entre los límites de las hojas y los límites políticos: economía gráfica versus "pureza geopolítica."

\section{Miniaturizar el mundo: geografías de bolsillo y mapas murales}

La fantasía de la mirada totalizante intrínseca al desarrollo de la cartografía occidental moderna (Cosgrove 2001) encarnó de manera casi modélica en el ambicioso proyecto de la Carte Internationale du Monde (o Mapa al Millonésimo) que aspiraba a compilar un mosaico de hojas topográficas a escala $1: 1.000 .000$ que cubriría toda la superficie del globo.

Por ese entonces varios países habían inaugurado o habían reorganizado instituciones específicas para relevar en forma homogénea la totalidad de la topografía de sus respectivos territorios a escalas de gran detalle. En 1809 el Ordnance Survey del Reino Unido había empezado los trabajos de triangulación que darían lugar a la serie de hojas de 1 : 63.360; en 1812, el General Staff Bureau de Suecia haría algo similar para la serie 1: $100.000 .^{3}$

En ese contexto, la producción de un mapa que representara toda la superficie terrestre de manera homogénea a una escala de 1:1.000.000 parecía ser un proyecto factible tanto en su dimensión institucional como en sus aspectos técnicos, e incluso contaba con un amplio consenso acerca de la utilidad potencial que tendría el hecho de consagrar esfuerzos a ese proyecto dada la relevancia socio-cultural que le daban sus contemporáneos.

Sin embargo, a pesar de su reducida escala, su pretenciosa cobertura hizo que la tarea pareciera casi tan quimérica y absurda como el mapa 1:1 de Borges. Así fue que pasaron casi veinte años entre el momento en que el geomorfólogo alemán Albrecht Penk lanzó la propuesta (primero en el periódico Allgemeine Zeitung el 20 de junio de 1891, 
y pocos días más tarde en el Congreso Nacional de Geografía de Berna) y la efectiva organización de una comisión que se encargaría de coordinar las tareas del ensamblado cuando las instituciones cartográficas de todos los países participantes hubieran enviado las hojas correspondientes.

En los Congresos Internacionales de Geografía de Londres (1895), Berlín (1899) y Washington (1905) se ratificó una y otra vez el apoyo al proyecto pero no se avanzó hacia ninguna directiva concreta que llevara a su materialización. En cambio, las resoluciones del Congreso Internacional de Geografía de Ginebra de 1908 derivaron en la creación de un comité que, ad hoc, que se ocuparía de encaminar el proyecto del mapa mundial al millonésimo. ${ }^{4} \mathrm{Al}$ año siguiente, una primera reunión diplomática convocada oficialmente por el gobierno británico y realizada en Londres en noviembre de 1909 marcaría el inicio de las actividades del International Map Committee. Se cursaron invitaciones a tantos gobiernos como fue posible, sin un criterio definido a priori, proponiendo participar de una reunión para conformar una comisión encargada de llevar adelante el proyecto de la Carta del Mundo al Millonésimo. Dicha Comisión se ocuparía de organizar reuniones periódicas, publicar un boletín que diera difusión a los progresos de los trabajos y, sobre todo, articularía una red de delegados representantes de cada uno de los estados suscribientes (International Map Committee 1910: 1-8). Es decir, el Committee funcionaría con autonomía respecto de los Congresos Internacionales de Geografía, bajo cuya órbita se había gestado. ${ }^{5}$

En efecto, el International Map Committee se reunió por primera vez en Londres en noviembre de 1909 y redactó un reglamento de trabajo (International Map Committee 1910) para acordar los criterios que se utilizarían para la representación de ciudades, caminos, límites, vías férreas, además de ratificar la adopción del meridiano de Greenwich como meridiano central y el sistema métrico decimal como sistema de medidas de distancias. $^{6}$

Cuando los delegados de Alemania, Austria, Hungría, España, Estados Unidos, Francia, Gran Bretaña, Italia y Rusia reunidos en la primera reunión de Londres de 1909 entendieron que si reunían todas cartas topográficas estándares, delimitadas por paralelos y meridianos en $4^{\circ}$ de latitud por $6^{\circ}$ de longitud (con excepción de las regiones polares en la que la cobertura de cada hoja sería de $12^{\circ}$ o más debido a la convergencia de los meridianos) esto iba a dar por resultado la faraónica cifra de 2.642 hojas. (International Map Committee 1910). ¿Cuál fue la solución que adoptaron? Pues decidieron limitar el trabajo a las superficies terrestres y ello redujo el número final de hojas a 840 .

En la segunda reunión, celebrada en París en 1913, se decidió que las poblaciones aparecieran clasificadas en un máximo de seis categorías y que, siempre que la escala lo permitiera, su perímetro se representaría respetando el contorno real de la mancha urbana de la jurisdicción. La altura del relieve sería representada con una escala cromática: el verde para las tierras bajas y el marrón en la zonas montañosas; las alturas intermedias recurrirían a diversas tonalidades ocres. Para representar las formas del relieve se usaría el sistema hipsométrico con curvas de 200; 500; 1.000; 1.500; 2.000; 2.500 metros (y se colorearía el espacio definido entre una curva de nivel y otra). También se determinó que todas las hojas llevarían un título general: "Carte Internationale du Monde au 1:1.000.000" y que, debajo, ese título general también aparecería en el idioma nacional del Estado que 
editaba la hoja (International Map Committee 1914: 81). Además, cada una llevaría por título el nombre del centro urbano o de la población más importante, acompañado de una clave mixta de números y letras. La signatura estaría precedida por la $\mathrm{S}$ o la $\mathrm{N}$, según se tratara del hemisferio norte o sur. Luego, le seguirían una letra y un número. Las letras se sucederían a partir del Ecuador, de la A a la V, y cada una de ellas definiría una zona de paralelos. Los números designarían husos de $6^{\circ}$, y se contarían del 1 al 60, a partir del meridiano $180^{\circ}$ hacia el Este. Las referencias de los signos convencionales se escribirían tanto en francés como en el idioma del país representado.

En la formulación del proyecto se decidió utilizar la proyección policónica modificada, pero finalmente se optó por la proyección cónica conforme de Lambert entre los paralelos $84^{\circ} \mathrm{N} \mathrm{y} 80^{\circ} \mathrm{S}$ y la proyección estereográfica en las zonas polares.

\section{La eternidad de lo provisorio}

Una de las particularidades de las hojas publicadas en el marco del IWM es que gran parte de ellas llevan la inscripción "Edición provisoria" en el ángulo superior derecho. Ello respondía a diversas circunstancias.

Por un lado, para evitar herir susceptibilidades, la AGS se había pronunciado explícitamente sobre el carácter provisorio de sus cartas y que la vigencia de las mismas regirá solamente "hasta que las oficinas nacionales los reemplazaran."

Por otro, se había acordado que las zonas poco conocidas serían representadas por líneas discontinuas o esfumados. En estos casos, las cartas debían tener la inscripción de Edición Provisoria. En particular, en este caso se esperaba que la consolidación de oficinas cartográficas de las burocracias estatales se comprometieran en el desarrollo de programas de levantamiento topográfico a gran escala y que lo hicieran adoptando los criterios sugeridos por este Proyecto para acelerar y facilitar el ensamblado de un mosaico de mapa del mundo a partir de hojas/partes que fueran compatibles entre sí. Se trataba de medir los accidentes topográficos y de volcar esos registros en un lenguaje normalizado que hiciera compatible el trabajo de diversos profesionales para el ensamblado de un mapa final conjunto razonablemente homogéneo. Pero no se publicarían mapas provisorios de cualquier cosa: se acordó que las zonas que no contaban con relevamientos y de las cuales no se tenía conocimiento no debían ser representadas. En otras palabras, esta idea de la "edición provisoria" implicaba haber al menos pasado un umbral de la "duda aceptable."

En el seno del Bureau, incluso, las ediciones provisorias fueron objeto de un debate arduo y llevaron a establecer una reglamentación específica que explicitaría los límites de lo aceptable, los márgenes dentro de los cuales se aceptaban imprecisiones de método y de reproducción. ${ }^{7}$ Las hojas provisorias fueron tantas (y tuvieron una vida larga, ya que la mayoría de ellas nunca fue reemplazada por una "definitiva") que pronto resultó insoslayable que esta "flexibilidad" ponía en duda la excelencia científica que estaba en la base de la filosofía del proyecto. Como respuesta al debate que se dio en el Congreso Internacional de Geografía celebrado en El Cairo en 1925, se decidió que cada hoja incluiría un cuadro que mediría y expresaría claramente la "confiabilidad de datos" (un recurso que ya había sido implementado en las hojas que recopilaba y publicaba la AGS) (Pearson y Heffernan 2008). El reporte dice explícitamente: “Technical questions. 
(1) Preparation of more definite regulations regarding the production of Provisional Editions. The old provisional Editions have now been cancelled and in future IM International Sheets must be layered and the degree of reliability of the information on the Map given in a diagram or note in the margin" (Bureau Central 1928: 5).

Tanto el Bureau Central del Mapa al Millonésimo y la AGS como el Instituto Geográfico Militar se vieron en la necesidad de recurrir a la categoría "provisional" para aceptar trabajos que no eran tan precisos o metódicos como hubieran deseado pero, al menos, permitían saldar la carencia de mapas sobre ciertas áreas.

Sin embargo, la categoría provisional no fue una cuestión meramente técnica, como sugerían los manuales y los reportes oficiales. En el caso de las hojas de la AGS, lo provisorio pasaría a indicar que se trataba de una hoja sujeta a aprobación por parte del o de los estados afectados en dicho mapa. En otras palabras, el uso del rótulo "provisorio" pasaría a ser utilizado en términos más políticos que técnicos. Y el caso argentino ofrece varios ejemplos acerca de esto.

\section{Argentina se suma al proyecto del mapa del mundo al millonésimo: entre la precariedad y la lentitud}

A pesar del interés y del compromiso expresado por las autoridades del Instituto Geográfico Militar, la producción de hojas topográficas a 1:1.000.000 se limitó a la publicación de tres hojas en 1911 que, aunque ajustadas al reglamento general de Londres de 1909, nunca fueron actualizadas para adaptarse a las exigencias del protocolo establecido en la reunión de París de 1913. El Informe de 1921 tiene una nota al pie que dice:

"Malheureusement, à cause de la guerre, les Compte-rendu de la Conférence de Paris ne furent pas reçus par le Directeur del Instituto Geográfico Militar avant que presque toutes les feuillies comprenant la République Argentine n’eussent été dessinées. On prend actuellement des mesures pour les dessiner de nouveau conformément aux résolutions de Paris" (Bureau Central 1921: 26).

Aunque esto nunca fue remediado, en los años siguientes, diversos miembros del Instituto Geográfico Militar siguieron asistiendo y participando de las reuniones de la Comisión sistemáticamente, pero no lograron aportar nuevos materiales más allá de aquellas tres primeras hojas - Buenos Aires, Concordia y Corriente - remitidas al Comité el 6 de abril de 1914.

Mientras que el Informe Anual del Bureau Central reporta que, en 1921, la Argentina prepara 18 hojas, ${ }^{8}$ el informe de 1923 parece ser más realista y sólo indica que se preparan dos (SI-19 y SJ-19, mientras que la SH-21 será publicada por Brasil bajo el nombre Uruguayana). Y esa situación se mantuvo sin cambios en los informes de las décadas siguientes. Algo similar ocurriría con el IWM-MMM. En el caso del Mapa del Mundo al Millonésimo, la ansiedad por avanzar con los trabajos a ritmos aceptables llevó a cometer diversos errores, tales como afirmar en el Reporte Anual que ciertas hojas ya habían sido publicadas cuando, en rigor, todavía no lo estaban: 
"Unfortunately last year the Central Bureau was rather premature in showing as published all the new sheets exhibited at the International Geographical Congress. It has seen ascertained that a number of theses were only proofs specially prepared for the Exhibition. The catalogue and the index diagrams accompanying this Report may not therefore agree with those published last year, but the now show the latest information available at the Central Bureau" (Bureau Central 1929: 7).

En 1926 el IGM apenas había terminado veintiséis hojas al 1:500.000, de las cuales se publicaron cuatro, a saber: Posadas, Paso de los Libres, Tres Arroyos y Chos Malal (IGM 1926: 162). ' Aunque algunos países usaron sus cartas 1:500.000 para armar las hojas al millonésimo correspondientes a su territorio y adaptadas a la grilla oficial del proyecto internacional (entre ellos, España ${ }^{10}$ ), esas hojas 1:500.000 del IGM no derivaron en ningún aporte al proyecto del mapa del mundo al millonésimo.

De un análisis rápido y superficial basado en estos datos de hojas publicadas, podría juzgarse que el Instituto Geográfico Militar fracasó rotundamente en su misión de contribuir a la producción de un mapa del mundo. Sin embargo, una mirada más atenta revela que los resultados de la inserción del Instituto Geográfico Militar y de otras instituciones científicas locales en la red internacional no pueden evaluarse sólo a la luz de las hojas producidas en los mapeamientos. Lo que perduró fue la manera particular de organizar los trabajos, que había sido tejida por la red de trabajo centralizada por el programa del mapa al millonésimo (Rieznik y Lois 2011). Las redes heterogéneas que se fueron tejiendo entre profesionales y funcionarios no sólo respondieron sino que también dieron forma, a las demandas sociales y a los problemas públicos, en gran parte, a través de prácticas asociadas a la representación del territorio argentino en las primeras décadas del siglo XX. El Instituto Geográfico Militar adoptó los protocolos de trabajo que delineaba la comunidad científica internacional, aunque su productividad fue lenta y errática.

En el marco del Hispanic America Map, la AGS publicó, entre 1920 y 1945, 405 hojas topográficas 1:1.000.000 correspondientes a América del Sur (algunas de ellas fueron publicadas más de una vez) (Pearson y Heffernan 2008). Cuando la AGS encaró el proyecto del Hispanic America Map para contribuir con las hojas correspondientes a los países latinoamericanos que no habían comprometido su producción nacional para el proyecto del Mapa del Mundo al Millonésimo, en principio no iban a ocuparse de la Argentina. Pero en el contexto de la escasa y lenta contribución del Instituto Geográfico Militar, la AGS contribuyó a la cobertura del territorio argentino al millonésimo: los reportes del Bureau Central incluían las hojas publicadas por la AGS en una lista aparte, titulada "List II. Index II. Sheet Published by Adhering Countries which do not conform to the accepted resolutions and sheets published by Private Societies." La AGS aportó las siguientes hojas sobre el territorio argentino: S J-18 Concepción (1930), S J-19 ParralNeuquén (1930), S H 19 Coquimbo - San Juan (1929), S K 19 Lago Nahuel Huapi (1930), S M 18 Isla Wellington - Lago Argentino (1928), S M 19 Santa Cruz (1930), S N 19 Tierra del Fuego (1930), S L-19 Comodoro Rivadavia (1932), S J 20 Bahía Blanca (1934., S N-20 Córdoba-Santa Fe (1935), S I-20 Rosario (1935), S J-21 Mar Del Plata (1935), S K-20 Golfo San Matías (1935), S G-20 Tucumán (1936). Para la elaboración de estas hojas, 
la AGS realizó un notable trabajo de compilación, comparación y actualización de un conjunto heterogéneo pero completo y exhaustivo de todas las fuentes disponibles - del que tenemos noticias gracias al meticuloso volumen donde se publicaron todas las notas cartobibliográficas de los materiales consultados (AGS 1933).

\section{Formas de reescritura: disputas metodológicas, políticas y científicas dirimidas en terrenos cartográficos}

La confluencia de actores, intereses y recursos que tenían diferente peso en el momento de producir cartografía y poner en circulación ciertas imágenes de los territorios mapeados generó una serie de polémicas que transcurrieron por varios carriles al mismo tiempo: por un lado, funcionarios de diferentes países intercambiaron materiales, demandas y reproches; por otro, hojas con "sutiles diferencias" eran publicadas al mismo tiempo por diferentes instituciones; y finalmente, también se fue imponiendo un debate tácito sobre la legitimidad de la autoría de los mapas y la pertinencia de que ciertos países representaran territorios ajenos.

Estas polémicas pueden ser abordadas y problematizadas desde diferentes ángulos. A menudo se ha privilegio el cotejo de los intercambios epistolares y otros documentos oficiales publicados por las instituciones involucradas. ${ }^{11}$ No obstante es posible indagar esas disputas a través de las diversas formas de reescritura que los actores pusieron en acción para defender su propia interpretación del territorio afectado. Ha sido una disputa un poco "más muda" que los elocuentes discursos y artículos que las figuras renombradas de la época hicieron sonar en la esfera pública. No obstante, el contrapunto entre esos discursos de intenciones y posicionamientos políticos, por un lado, y las sutiles o brutales diferencias que se observan en las hojas topográficas efectivamente publicadas, por otro, nos permite cuestionar la naturaleza de las disputas y el uso de la cartografía como terreno de combate para dirimir tales disputas con objetos de facto (los mapas) y no con meros discursos de circulación más que restringida.

\section{Polémica \# 1. En torno a la confiabilidad de las fuentes y la obtención de datos}

La AGS publicó en 1932 dos hojas provisorias SL-19 Comodoro Rivadavia, una en "blanco y negro" (en realidad, también usa el rojo y el azul, pero llamaremos así a las hojas despojadas de paleta cromática para representar la altura de los relieves) y otra coloreada (Figuras 1 y 2). 


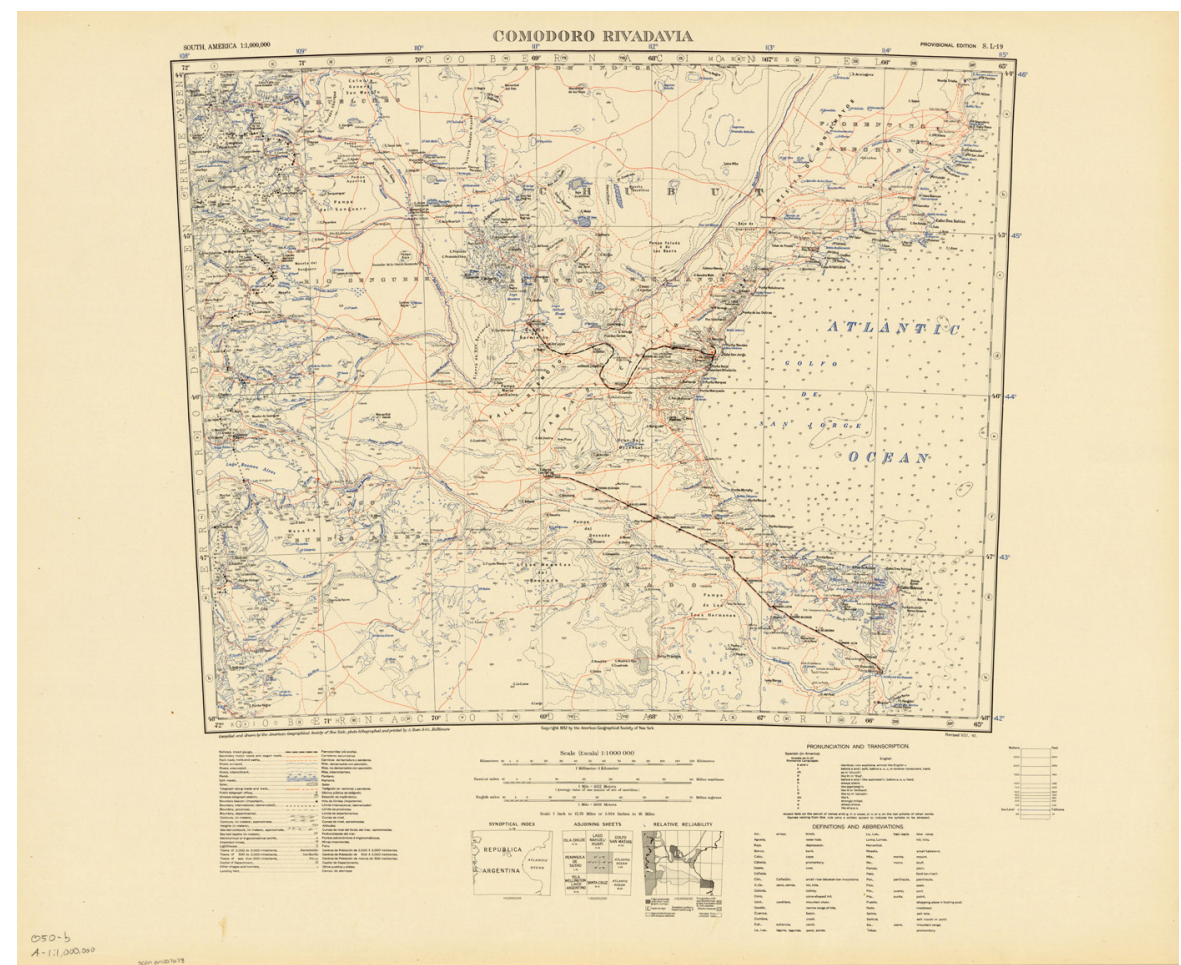

Figure 1. Hoja topográfica 1:1.000.000 SL-19 Comodoro Rivadavia (AGS 1932).

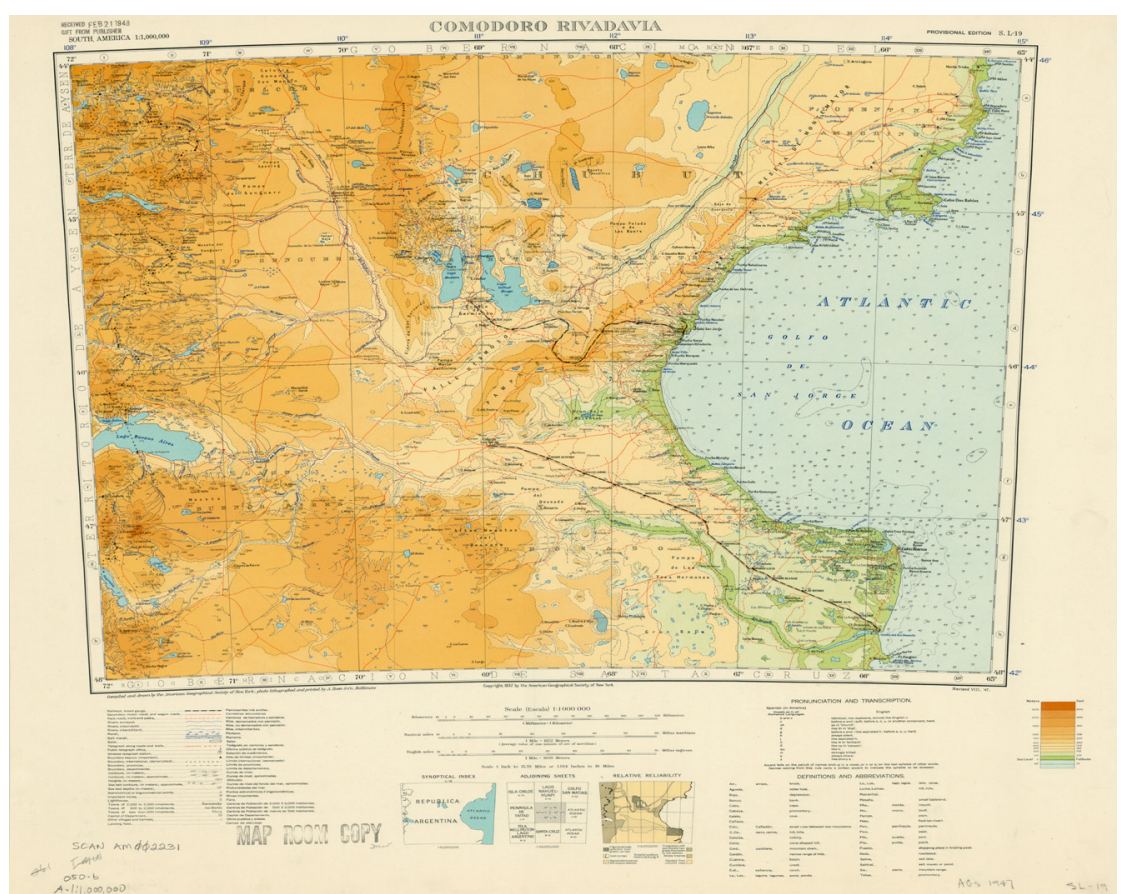

Figure 2. Hoja topográfica 1:1.000.000 SL-19 Comodoro Rivadavia (AGS 1932). 
En 1952, el Instituto Geográfico Militar reeditó la misma hoja (Figura 3). Sin bien las hojas norteamericanas y la argentina representan de manera casi idéntica el territorio cubierto, hay cuatro cuestiones que marcan significativas diferencias entre ambas:

Primera, la hoja argentina tiene unas enmiendas en negro, que tapan información preexistente. Las dos inscripciones más visibles en el mapa son "Chubut" y "Santa Cruz", es decir, los nombres de las provincias abarcadas en la hoja (por otra parte, hay que mencionar que se trataba de territorios recientemente provincializados, que desde 1884 eran territorios nacionales sin estatus provincial), y apenas se puede reconocer el nombre de la localidad que da título a la hoja.

Segunda, entre las hojas de ambas instituciones, hay diferencias de los criterios de confiabilidad de las fuentes y de la obtención de datos. Las hojas de la AGS muestran seis categorías que clasifican las diferentes fuentes de información y, especialmente, los diferentes métodos de relevamiento que se asociaban a variables grados de precisión. Eso da por resultado una superficie heterogéneamente relevada, donde sólo un par de pequeñas superficies han sido medidas trigonométricamente, y en la zona de frontera entre Chile y Argentina se concentran los trabajos de triangulación y una serie de puntos acotados. En cambio, la hoja argentina prefiere marcar casi la totalidad de la superficie cubierta por relevamientos expeditivos. Evidentemente existían áreas relevadas y medidas con métodos de alta precisión (en particular, aquella afectada por los trabajos de la demarcación del límite internacional). Pero indicar esas zonas y ese tipo de trabajos topográficos implicaba admitir la escasez y lo limitado de tales relevamientos, incluso treinta años después de lo que mostraban las hojas de la AGS (Figura 4).

Tercera, la hoja argentina ha eliminado la leyenda "Edición Provisoria," aunque admite que su confección está basada en relevamientos expeditivos. Se privilegió que la imagen sugiriera un reconocimiento homogéneo de la zona, aunque se traten de operaciones más precarias desde el punto de vista técnico, antes que admitir que poco se había avanzado respecto de los estudios realizados tres décadas antes. Se recurre a la autoridad del responsable o autor institucional para afirmar el carácter definitivo de la hoja y, por ende, superador de las versiones anteriores.

Finalmente, la hoja argentina elige trasgredir el margen izquierdo del borde de la hoja para incluir un pequeño fragmento de territorio argentino que, en cambio, en las hojas americanas aparece representado en la hoja adyacente. El IGM prefiere no atenerse a un criterio puramente cartográfico y, en cambio, opta por asumir como objetivo principal la representación cartográfica de todo el territorio nacional en sus hojas. 


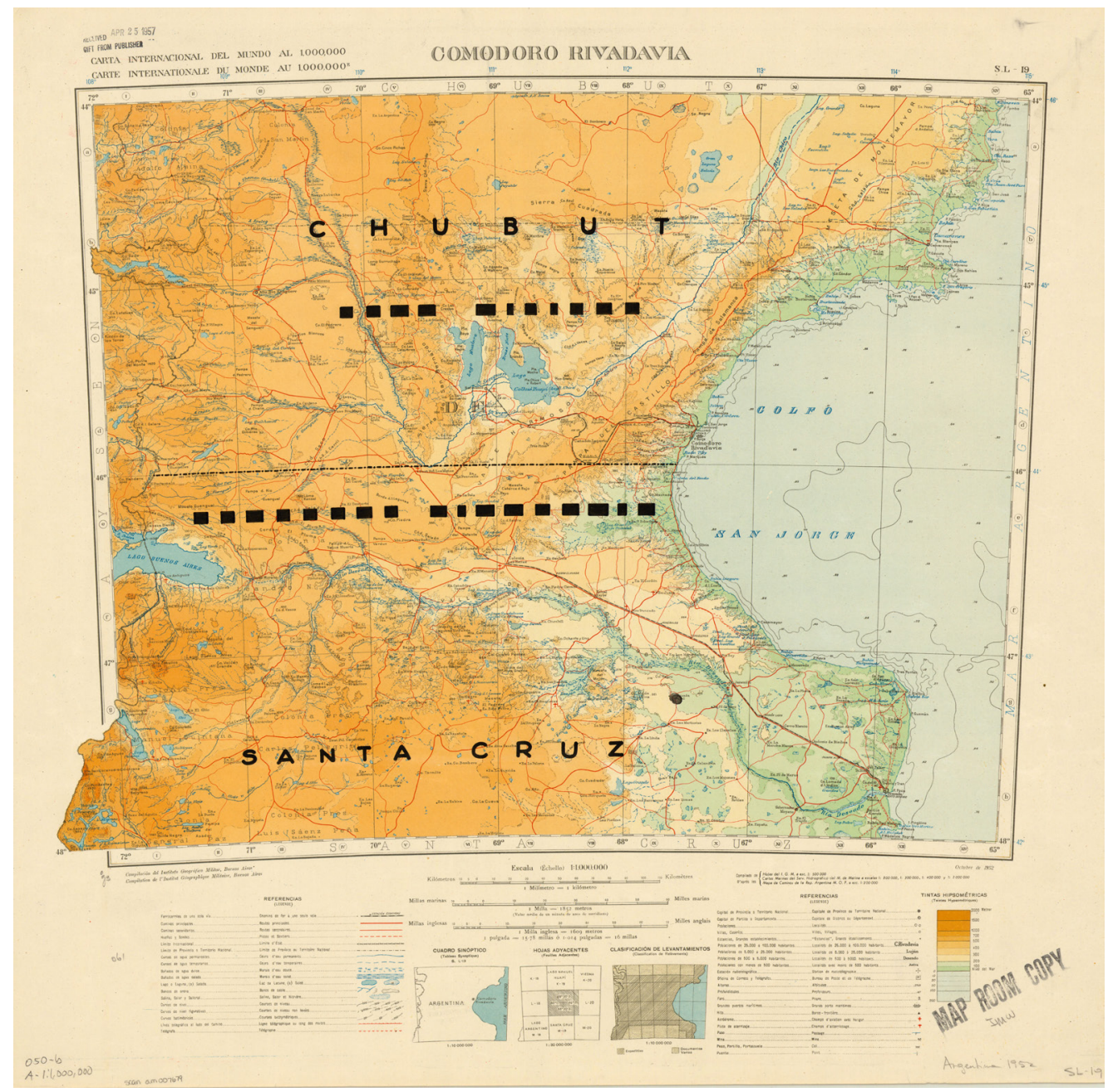

Figure 3. Hoja SL-19 Comodoro Rivadavia (IGM 1952). Se destacan la sobreimpresión de los nombres de los territorios nacionales "Chubut" y "Santa Cruz." Es difícil conjeturar acerca de la leyenda censurada con tachaduras negras, pero probablemente aludan a su carácter Jurídico precario: se trataba de territorios nacionales y gobernaciones militares (cuyos habitantes no tenían derechos ciudadanos) y que sólo fueron provincializados en 1955. Nótese que en el margen izquierdo, el territorio "rompe" el margen de la hoja topográfica para no excluir una pequeña porción de territorio argentino. 

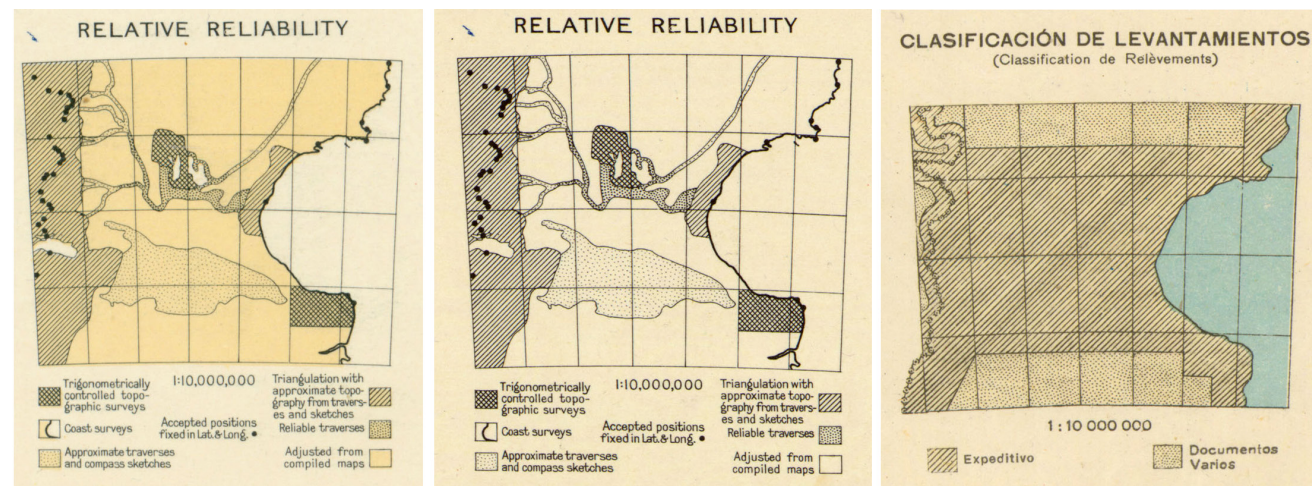

Figure 4. Detalles de las tres hojas SL-19 Comodoro Rivadavia, de Figura 2, Figura 1 y Figura 3 izquierda a derecha respectivamente. Las dos primeras imágenes (AGS 1932) expresan claramente diferentes grados de confiabilidad de los datos según los métodos de obtención de datos. En la tercera imagen, el IGM (1952) ha optado por eliminar los vacíos que indicaban la falta de relevamientos y, en cambio, afirmar que la totalidad del área había sido cubierta por relevamientos expeditivos.

Es interesante comparar estas prácticas con lo que ocurrió en la parte no hispana que completaría el mapa de América del Sur. En rigor, Brasil fue una insólita excepción en América Latina: contrariamente a la falta y a la lentitud de contribuciones al proyecto del mapa al millonésimo, en 1922 Brasil presentó un atlas que compilaba las 45 hojas topográficas en 1:1.000.000 del territorio brasileño. Su programa cartográfico se plegaba adecuadamente al proyecto del mapa del mundo al millonésimo. Esta atlas siguió reeditándose hasta finales del siglo XX con correcciones y adiciones.

En 1959, el Conselho Nacional de Geografia redibujó la hoja SH-21 que imprimiría el Servicio Gráfico del IBGE (Instituto Brasileiro de Geografia e Estatística). En ese entonces, ya no lleva la inscripción "Hoja provisoria," de manera análoga a lo que publicaban las instituciones argentinas en ese momento (véase el caso ya mencionado de Comodoro Rivadavia), como si el estatus de "provisorio" admitiera alguna duda sobre la soberanía que el estatus de "hoja definitiva” permitiera finalmente saldar. Por otra parte, ha retirado el subtítulo Brasil y, aunque tiende a darle cierta uniformidad cromática a la hoja y por tanto no se destaca a simple vista el territorio brasileño con la misma potencia que en la hoja de 1929, sigue optando por distinguir el territorio brasileño con los topónimos de los estados internos mientras que usa los nombres genéricos de los países para los territorios de los estados vecinos. Desde el punto de vista técnico, la principal innovación de esta hoja son los relevamientos aerofotográficos.

Hacia mediados del siglo XX, la autoridad institucional de las oficinas cartográficas nacionales reemplazó el criterio que había primado hasta entonces para definir la provisionalidad de las hojas, es decir, la evaluación crítica de las fuentes de información y los tipos de relevamiento topográfico. Era una señal de un proceso más profundo: los proyectos cartográficos nacionales quedaron subsumidos en discursos cartográficos nacionalistas. 


\section{Polémica \# 2. ¿Dificultades metodológicas o pugnas políticas?}

Numerosas dificultades afectaron la continuidad del proyecto, muchas de ellas debidas a lo ambicioso del programa y a su larga duración - con las lógicas interrupciones forzosas que se impusieron durante los periodos de grandes crisis y las guerras mundiales.

Algunos de los obstáculos más mencionados en las fuentes que registran las etapas del proyecto son las dificultades metodológicas que se suscitaban durante la ejecución del proyecto y la recolección del material enviado por parte de los Estados. Por ejemplo, la dificultad para alcanzar la homogeneidad de criterios era una preocupación de la época, así lo demuestra un artículo escrito por Haardt de Hartenthurn, Consejero Ministerial en el Real e Imperial Instituto Geográfico de Viena, y publicado en la revista Petermanns Mitteilungen en 1914: "la discusión sobre signos cartográficos para las distintas clase de caminos etc. puso igualmente en evidencia la gran dificultad, o más bien, la imposibilidad de llegar a una uniformidad completa para todas las hojas de la Carta" (citado en IGM 1914: 104). Las geografías heterogéneas atentaban contra viabilidad de pactar pautas homogéneas de trabajo y de cumplir el sueño del "mosaico prolijamente coherente" tanto en sus principios cartográficos como en su apariencia estética y criterios gráficos. En el primer anuario del Instituto Geográfico Militar (IGM 1912) se publicó un artículo que refiere a la situación del mapa mundial al millonésimo. En él se repasa la situación de los países en sus respectivos trabajos cartográficos y las disposiciones internacionales adoptadas en los congresos internacionales reunidos a tal efecto (en particular se destaca la adopción del meridiano de Greenwich como referencia, como resultado de la desestimación de la pretensión francesa de utilizar el de París a cambio de prescindir de sistema de medidas inglés y adoptar el métrico decimal). También se comenta la propuesta que hizo el IGM para adaptar la simbología propuesta por los países europeos a la "realidad sudamericana" (IGM 1912: 4) ya que el Instituto entendía que los países sudamericanos tendrían las siguientes dificultades para integrarse al proyecto del mapa mundial: (1) el trazado de las líneas limítrofes con los países vecinos; (2) la aplicación de los signos de la Conferencia de Londres (1909) a "ciertas particularidades de los países sudamericanos"; y (3) la inexistencia de cartografía fehaciente" (IGM 1912: 5; los destacados son nuestros).

Se multiplicaron los pedidos de excepciones para utilizar signos no previstos en el vademécum cartográfico oficial para representar las singularidades de las respectivas geografías nacionales. No obstante ellos, el debate era sólo una puesta en escena del ejercicio de potestad sobre la cartografía que todas las naciones querían dejar sentado en documentos oficiales. En lo que concierne a la producción cartográfica: en la mayoría de los casos, simplemente cada país resolvió su agenda cartográfica según sus propios criterios sin que ello generara grandes controversias metodológicas. La prolongación en el tiempo del programa del mapa al millonésimo impuso nuevos desafíos y obstáculos a sortear. En el momento de la formulación del proyecto, se proponía reunir tanta información como fuera posible. Pero cuando el volumen de datos fue tal que no era posible seguir agregando cosas sin adoptar algún criterio de selección relativamente estable para todas las hojas, se plantearon nuevas preguntas: “¿Debe ser enfatizado el sistema de comunicaciones o el relieve? ¿Los aspectos militares o políticos o económicos deben ser considerados para su 
representación?” (Crone 1962: 38). En efecto, hacia mediados de siglo, el mundo había cambiado y el mapa del mundo debía ser adaptado para servir a los propósitos que se habían propuesto. Los cambios más mencionados eran la transformación radical de las redes de transporte, las innovaciones tecnológica en la producción y reproducción de mapas (principalmente debido a la introducción de la fotografía aérea) y el desarrollo del proyecto cartográfico de la International Civil Aviation Organization.

Más delicado fue el asunto de la "tutela": en la conferencia de Londres de 1909, se resolvió que aquellos países que no contaran con instituciones cartográficas serían mapeados por otros que sí las tengan y dispongan de recursos suficientes para hacerlo. ¿Con qué criterios se decidiría este punto? Aunque en apariencia se trataba de una mera cuestión de posibilidades técnicas que ciertos países no podían garantizar para producir mapas y que por tanto, provisoriamente, serían suplidos por otros, los reclamos diplomáticos revelan que esas decisiones encubrían aristas insospechadas: en esa misma reunión de 1909 se acordó encargarle a Alemania la realización de los mapas de China y de Asia en general. El delegado de Japón, el Coronel Sundzouma, hizo notar en el congreso de Roma de 1913 que su país ya contaba con avances significativos en materia cartográfica y destacó que "el Japón ya estaba ocupado, desde hacía varios años, en la confección de un mapa a la misma escala del mapa mundial, cuyas hojas podían ajustarse a la red del mismo" (IGM 1913: 126), por lo que reclamaba que el Japón quedara encargado de la construcción de las hojas de una parte de las hojas de Asia (véase Mazzitelli 2008: 46-47).

\section{Polémica \# 3. Tensiones entre los objetivos internacionales y los intereses nacionales}

En el mismo sentido, uno de los cambios que también afectó el desarrollo del IWM / MMM fue el desarrollo de oficinas cartográficas en países que no contaban con ellas en los primeros tiempos del proyecto y, sobre todo, el eventual conflicto de intereses que se daba entre la manera de representar la geografía políticas según los lineamientos del Comité Central y según las pretensiones territoriales de los estados particulares. No obstante, esta preocupación, a menudo definida en términos estrictamente prácticos (habitualmente bajo el rótulo de guías de trabajo, técnicas de impresión, factibilidad de construir el mosaico completo, etc.) también tenía una arista política. De hecho, en los debates y en las propias hojas pueden leerse, más o menos explícitamente, los intereses de cada uno de los estados involucrados por representar sus pretensiones territoriales a los efectos de imponer discursos científicos que legitimaran sus reivindicaciones en la arena internacional. Por ejemplo, en 1934, el Comité decidió que el Informe Anual incluiría los informes parciales presentados por los países participantes (Union Géographique Internationale 1934). Se trataba de una novedad: no era el propio Comité el que narraba el estado de situación sino que se le otorgaba voz a los distintos actores involucrados. Los documentos remitidos por las diferentes instituciones fueron traducidos al francés, pero no sufrieron ningún tipo de edición o modificación que alterara el contenido del informe. Así se lee que "le contour de cette carte [el mapa de la Argentina] suit exactement nos frontières" (citación completa 5; los destacados son nuestros). Se omite cualquier referencia a tratados internacionales de límites, a cualquier información "objetiva," y se 
adopta un vocabulario que, lejos de ser neutral, asume que la Argentina es un sujeto de pleno derecho en la diplomacia internacional.

Anticipándose a los problemas del tutelaje y bajo la marca del trabajo científico colaborativo, algunos estados latinoamericanos que no alcanzaban a producir sus propias hojas topográficas ni informes, decidieron aliarse a la AGS de diferentes maneras. Ecuador proporcionó a la entidad neoyorkina la colección entera de relevamientos topográficos inéditos e incluso contribuyó financieramente (AGS 1946). Esa aparente inocente voluntad de contribuir al progreso del proyecto de la AGS generó no pocos conflictos. Uno de ellos fue que el presidente del Perú, país colindante que mantenía disputas de límites con Ecuador, por ese entonces había decretado que no se importarían mapas producidos en el extranjero que no estén en sintonía con los reclamos territoriales peruanos, y se consideró afectado por el uso de fuentes ecuatorianas para la publicación de ciertas hojas del Map of Hispanic America. Finalmente, ante del reclamo del presidente peruano - que argumentaba que una institución científica "políticamente desinteresada" no podía tomar partido por ninguna de las partes involucradas en disputas territoriales - la AGS respondió personalmente al mandatario de Perú afirmando que se comprometía a publicar hojas que representaran todas las posturas de los territorios en conflicto para no legitimar ninguna de las posiciones en pugna. Tras aceptar este compromiso, un nuevo decreto peruano exceptuó a las hojas de la AGS de la restricción a las cartografías importadas (AGS 1946: 8).

\section{Polémica \# 4. Los conflictos geopolíticos: las islas del Atlántico Sur}

Una de las hojas más australes de la serie publicada por la AGS en 1930 era la titulada "Tierra del Fuego" (Figura 5) e incluía en un recuadro el Departamento de la isla de los Estados adscripto a la Gobernación de la Tierra del Fuego. Se ajustaba así a uno de los artículos del reglamento acordado en 1913 en el que se sugería que las hojas llevarían por nombre el topónimo urbano o geográfico más relevante del mapa.

Sin embargo, el Instituto Geográfico Militar optó por publicar en 1952 una nueva hoja titulada "Isla de los Estados" (Figura 6), aunque la isla en cuestión ocupa una pequeña porción de la hoja en el margen izquierdo mientras que el recuadro con las Islas Malvinas protagoniza el mapa y, más todavía, esa caja recuadra es secundado por otra en donde se representa el triángulo antártico pretendido por la Argentina a una mayor escala. Evidentemente, dado que el mapa estaba dirigido tanto al público argentino como a la audiencia internacional que seguía los progresos del proyecto del Mapa del Mundo al Millonésimo, no parecía políticamente acertado titular la hoja en cuestión con aquellos objetos geográficos que, si bien eran los que preponderaban en el mapa también eran objeto de disputa territoriales vigentes. 


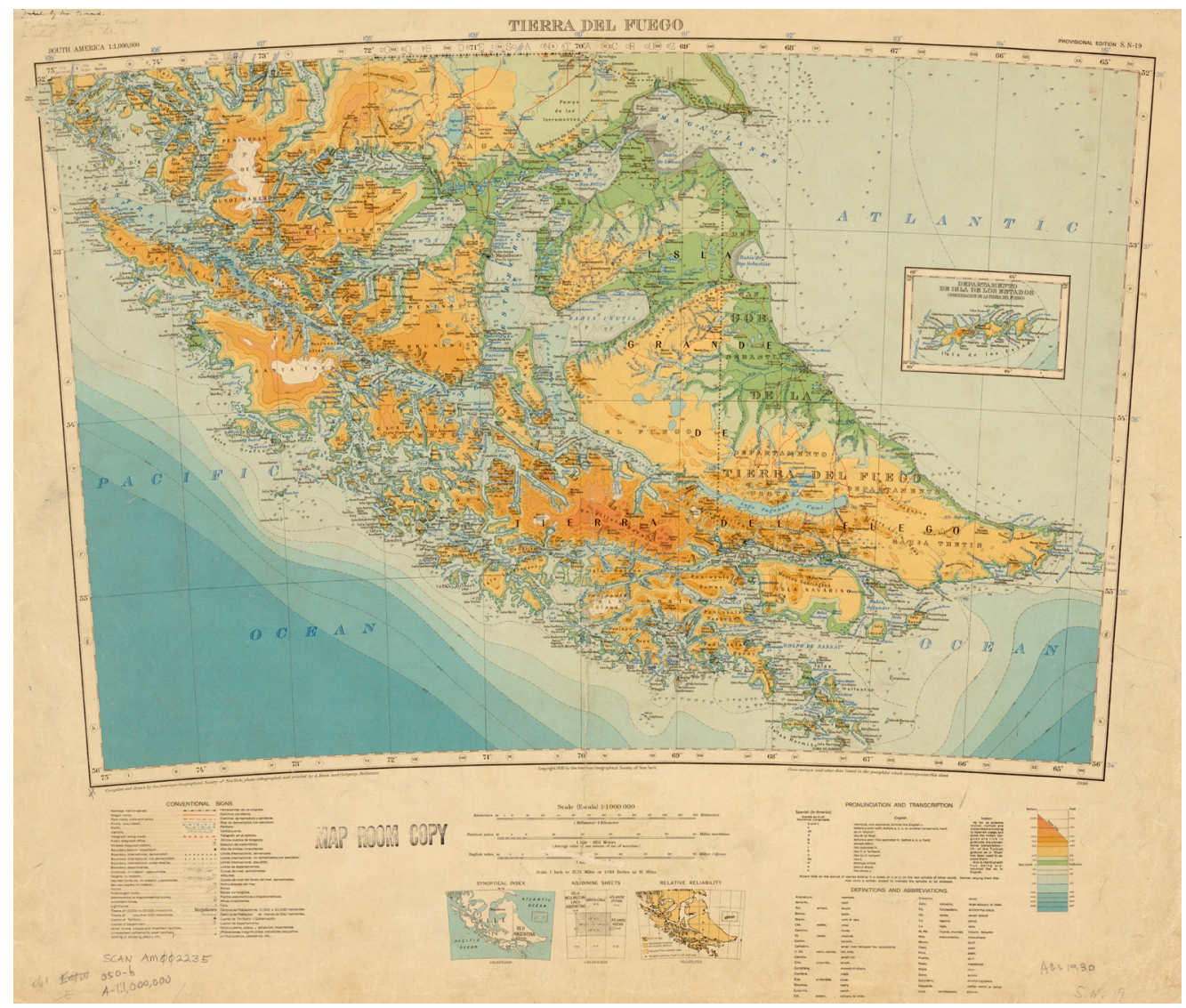

Figure 5. "Tierra del Fuego.” American Geographical Society, South America 1:1.000.000 (1930). En la hoja se representa la totalidad de la isla de Tierra Fuego y el límite político que separa la parte chilena de la argentina apenas es distinguible. 


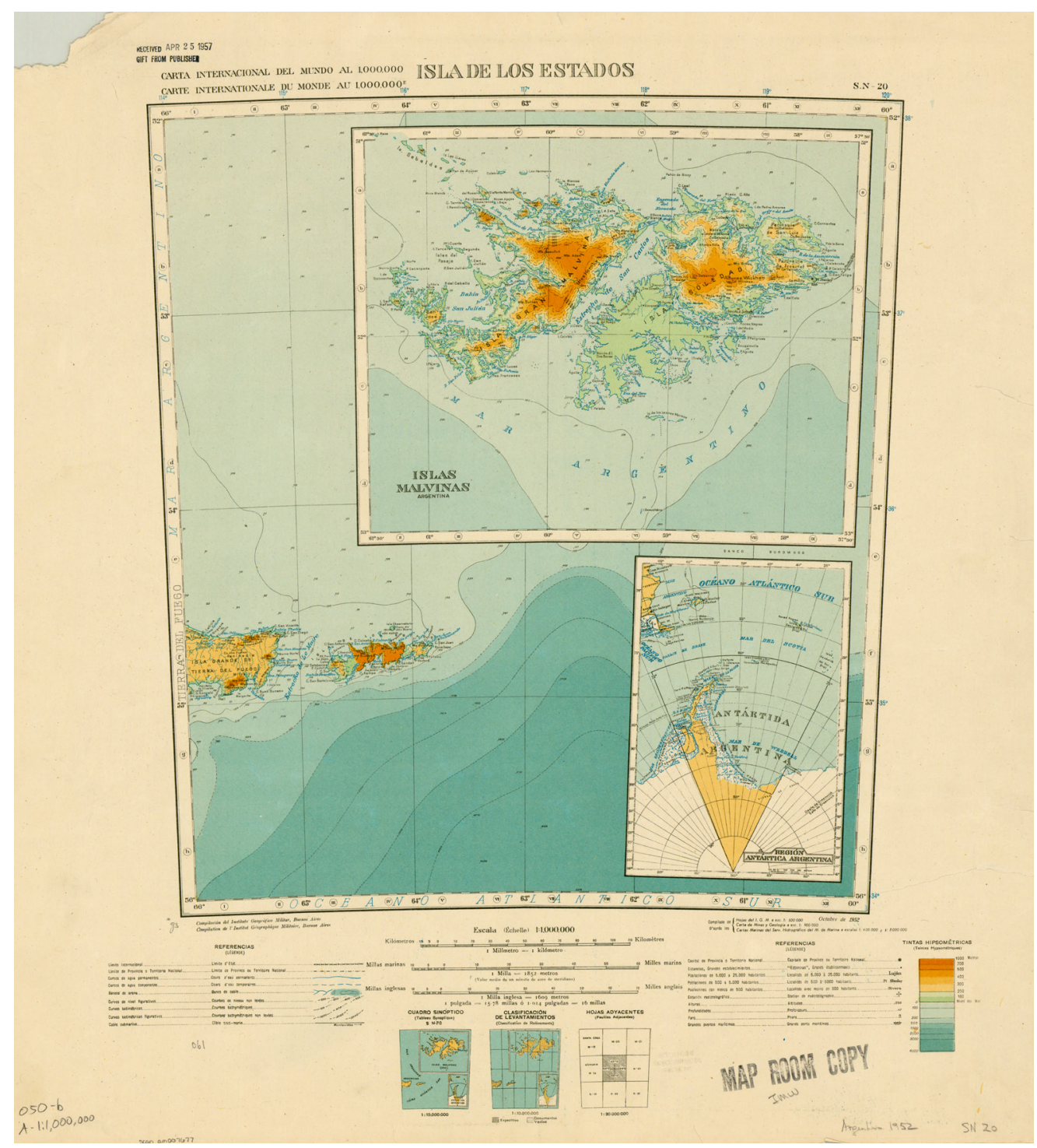

Figure 6. "Isla de los Estados.” Instituto Geográfico Militar 1:1.000.000 (1952). Aunque las hojas debían llevar por nombre la localidad o el elemento geográfico destacado, la isla que da título a esta hoja es notablemente pequeña en comparación con el tamaño que tiene los territorios demandados por el Estado argentino (sobre los que no posee soberanía efectiva). En el diseño de esta hoja primaron los reclamos y los criterios políticos.

El IGM tampoco estimó conveniente minimizar la visualización del reclamo de soberanía del gobierno argentino y dejar que esos territorios reclamados ocuparan un lugar marginal en la hoja de Tierra del Fuego en su hoja de 1952. Así podemos ver que otra de las novedades que incorpora la hoja "Isla de los Estados" a diferencia de la hoja "Tierra del Fuego" de la AGS, el sector antártico reclamado por la República Argentina es incluido en 
un recuadro. No se trató solamente de una estrategia gráfica. Por el contrario, la gestión de esa nueva imagen se inscribía dentro de un conjunto variado de políticas públicas que iban desde la creación de instituciones (tales como la creación del Instituto Antártico Argentino), la instalación de bases científicas ${ }^{12}$ y la organización de expediciones polares hasta la incorporación de este temario a la currícula escolar (García 2009; Hollman y Lois 2011) y también la legislación sobre la imagen cartográfica propiamente dicha. Al mismo tiempo, el sector pretendido por el Estado argentino pasaba a ser mensurado y contabilizado dentro del inventario patrimonial del Estado: en 1947, el Servicio Estadístico Nacional (más tarde, INDEC), en ocasión del levantamiento del Cuarto Censo Nacional, incluyó por primera vez la jurisdicción denominada "Sector Antártico e Islas del Atlántico."13 Los manuales escolares se hicieron eco de esta agenda política. Por un lado, la incorporación de la Antártida llevó a la reescritura de ciertos episodios de la historia territorial que, por cierto, adoptaron un tono cada vez más nacionalista. En 1939 el libro Geografía $4^{\circ}$ año para la educación secundaria de Lorenzo Dagnino Pastore se decía que Gran Bretaña "posee” más de ocho millones kilómetros cuadrados en los que incluye mares y la Antártida ahí mismo designada como una dependencia de las Falkland Islands. Pero en 1940 el autor cambió la palabra "posee" por la expresión "se atribuye" y agregó que la Argentina debería tener parte de ese territorio si el criterio para la distribución de la Antártida fuera aplicado. En 1944 radicalizó sus afirmaciones y llegó a sostener que la Argentina tiene “incuestionables derechos" y en 1946 afirmó que la Argentina ha hecho conocer al mundo sus reclamos sobre el sector antártico sobre el que tiene derecho. Finalmente en 1947 escribió como si fuera un hecho que la Argentina "ejerce autoridad" sobre un sector de la Antártida (Dagnino Pastore 1939; 1940; 1944; 1946). ${ }^{14}$

En sintonía con esta política cartográfica y en el contexto de la oficialización del reclamo de soberanía o derechos que hizo el Estado argentino sobre una porción de la Antártida, el Instituto Geográfico Militar había publicado en 1946 el "Mapa de la Zona Austral" a escala 1:3.000.000.

Esta política cartográfica fue llevada al extremo cuando el IGM hizo una grilla análoga para el sector antártico sobre el que la República Argentina reclamaba soberanía (Figura 7).

Al sobreimprimir la cuadrícula de la grilla "científica" del MMM procura transferir la legitimar del proyecto cartográfico al terreno de las demandas diplomáticas. Hoy sabemos que esto no ha tenido ningún impacto real o práctico en la administración de esos territorios, pero simbólicamente el Estado argentino se atribuía la potestad de cartografiar esos territorios en disputa como propios. 


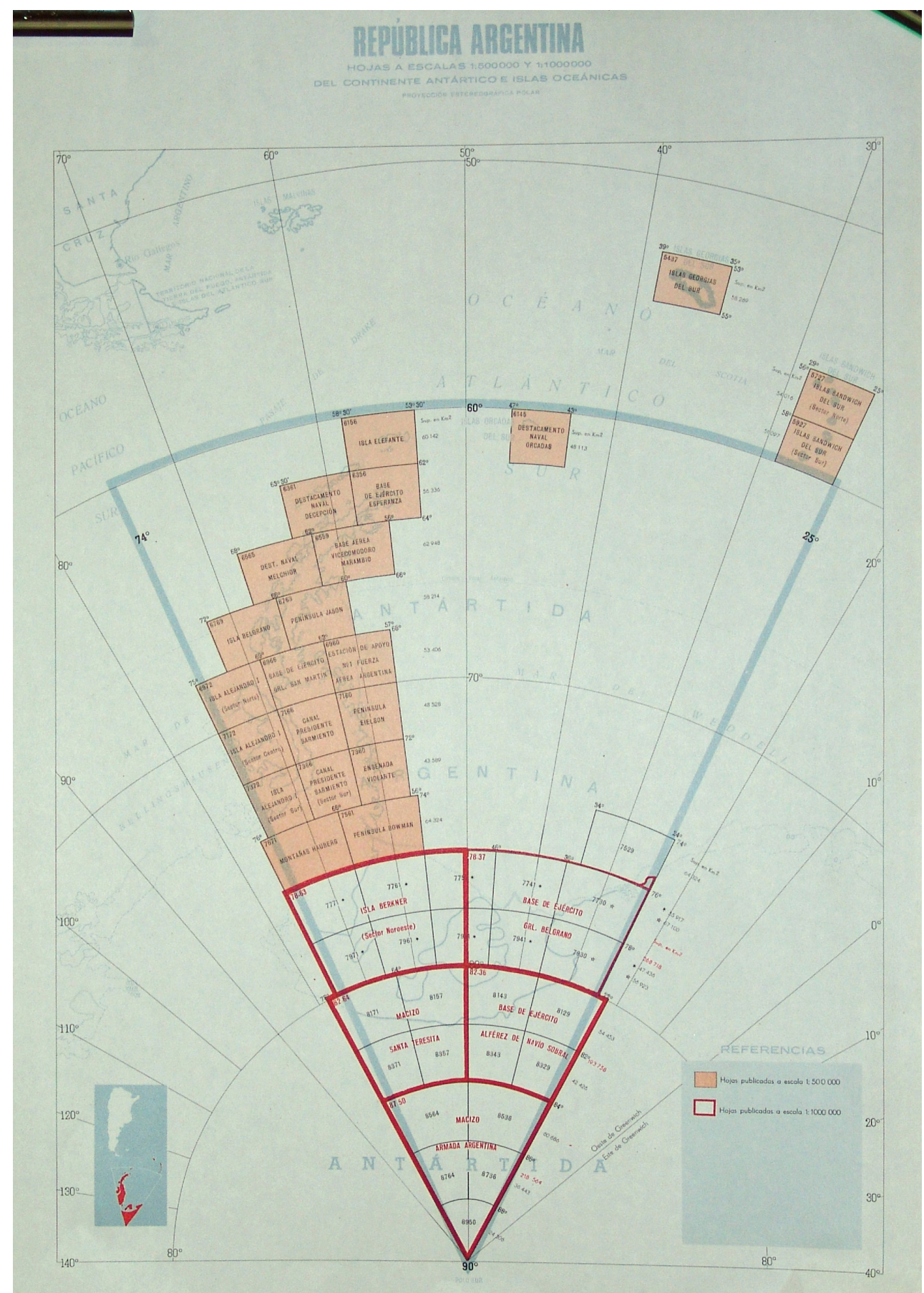

Figure 7. "República Argentina." Hojas a escalas $1: 500.000$ y $1: 1.000 .000$ del continente antártico y de las islas oceánicas. La mayor parte de las hojas incluyen en su nombre expresiones tales como "Dest. Naval...," "Base de apoyo...," "Base de Ejército..." La hoja más austral tiene por título "Macizo Antártida Argentina." 


\section{Polémica \# 5. Los límites de las hojas y los límites políticos: economía gráfica versus "pureza geopolítica"}

Los bordes de las hojas, la forma de seccionar o diseccionar fragmentos de territorios y las licencias toponímicas a menudo tuvieron que dirimirse entre optar por un criterio de economía gráfica que maximizara los recursos financieros para la publicación de hojas y los conflictos de intereses que implicaba publicar mapas del territorio de un estado al mismo tiempo que tanto ese estado como ese territorio se estaban construyendo y consolidando.

En 1930, la AGS publicó la hoja Nahuel Huapi (Figura 8), compilada y dibujada por la AGS y fotolitografíada por A. Hoen y Co. Baltimore. La hoja cubre solamente el territorio argentino (en el índice sinóptico "Synoptical Index" que acompaña el mapa eso queda explicitado, y en el esquema de las hojas adjuntas "adjoining sheets," queda claro que las tres hojas de la columna izquierda corresponden al territorio chileno).

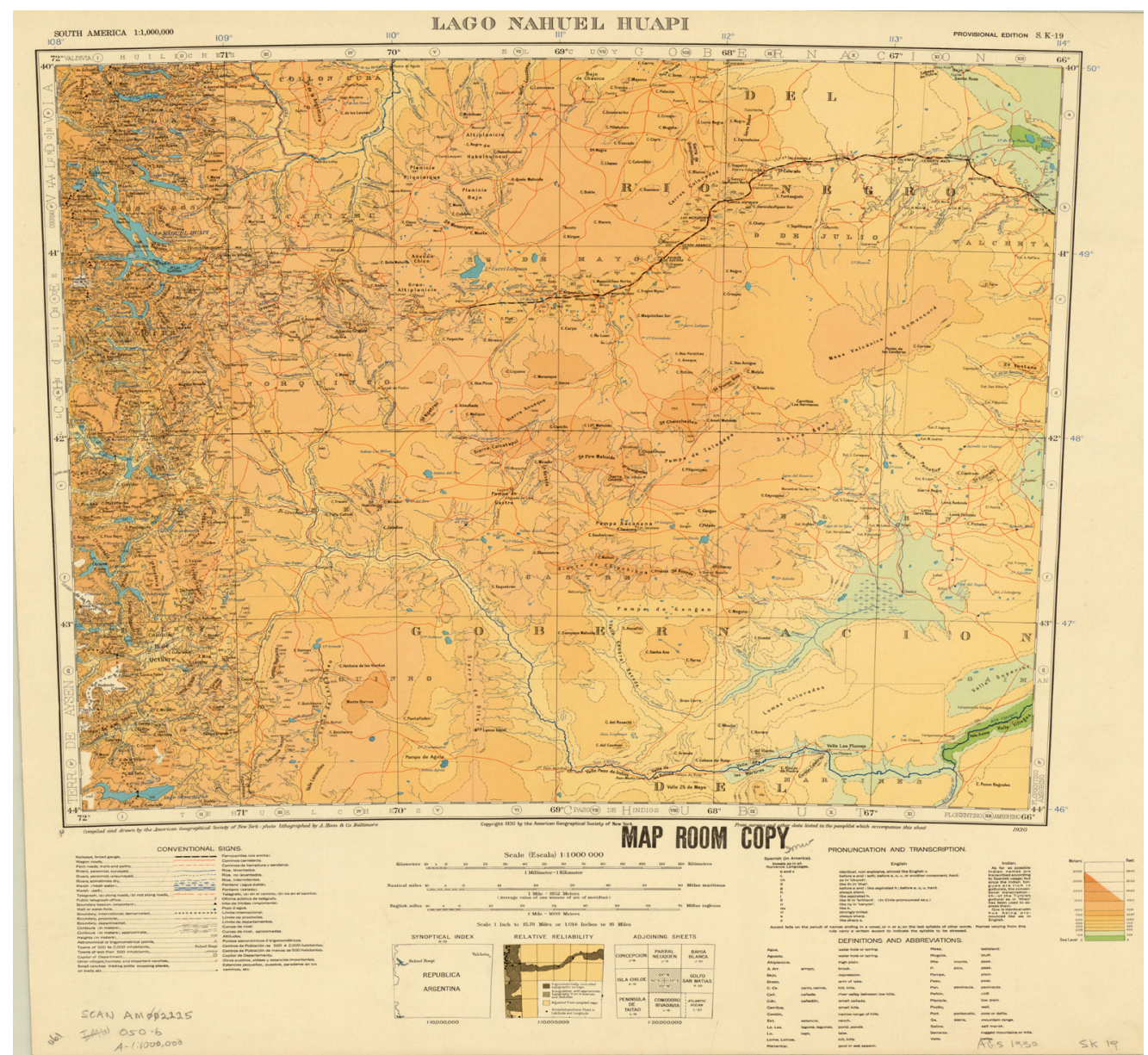

Figure 8. "Lago Nahuel Huapi." K 19 (AGS 1930). Esta hoja se adecua a todas las normativas del reglamento fijado por el Comité del MMM: lleva por nombre el objeto geográfico más destacado y se ajusta a una sola celda de la cuadrícula modelo (véase detalle, Figura 9). 


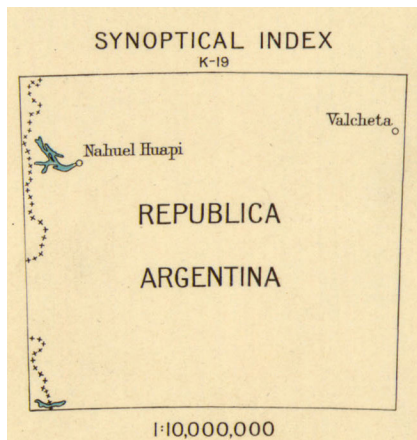

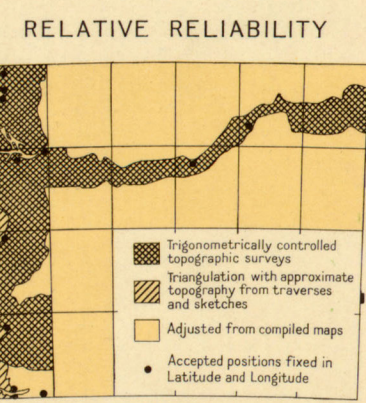

I:10,000,000
ADJOINING SHEETS

\begin{tabular}{|c|c|c|}
\hline$\underset{\mathrm{J}-18}{\text { CONCEPCION }}$ & $\begin{array}{c}\text { PARRAL } \\
\text { NEUQUEN } \\
J-19\end{array}$ & $\begin{array}{c}\text { BAHIA } \\
\text { BLANCA } \\
J-20\end{array}$ \\
\hline$\underset{\kappa-18}{\text { ISLA CHILOE }}$ & $\begin{array}{c}42^{\circ} \mathrm{S} / 42^{\circ} \\
69^{\circ} \mathrm{w}\end{array}$ & $\begin{array}{c}\text { GOLFO } \\
\text { SAN MATIAS } \\
k-20\end{array}$ \\
\hline $\begin{array}{c}\text { PENINSULA } \\
\text { DE } \\
\text { TAITAO } \\
\text { L-18 }\end{array}$ & $\begin{array}{c}\text { COMODORO } \\
\text { RIVADAVIA } \\
{ }_{L-19}\end{array}$ & $\begin{array}{l}\text { ATLANTIC } \\
\text { OCEAN } \\
L-20\end{array}$ \\
\hline
\end{tabular}

1:30,000,000

Figure 9. Detalle de hoja K 19 Lago Nahuel Huapi (AGS 1930). El recorte de la hoja se ajusta estrictamente a la cuadrícula del MMM, sin considerar que pequeñas áreas de territorio argentino quedan incluidas como porciones mínimas en las hojas adyacentes donde predominan los territorios chilenos.

Sin embargo, la misma institución, en 1956, reunió en una misma plancha hojas que, según la grilla original, correspondían a dos hojas diferentes: así, la hola SK18-19 (Figura 9) junta territorios argentinos y chilenos en una sola hoja retitulada Puerto Montt-Río Chubut (Figura 10).

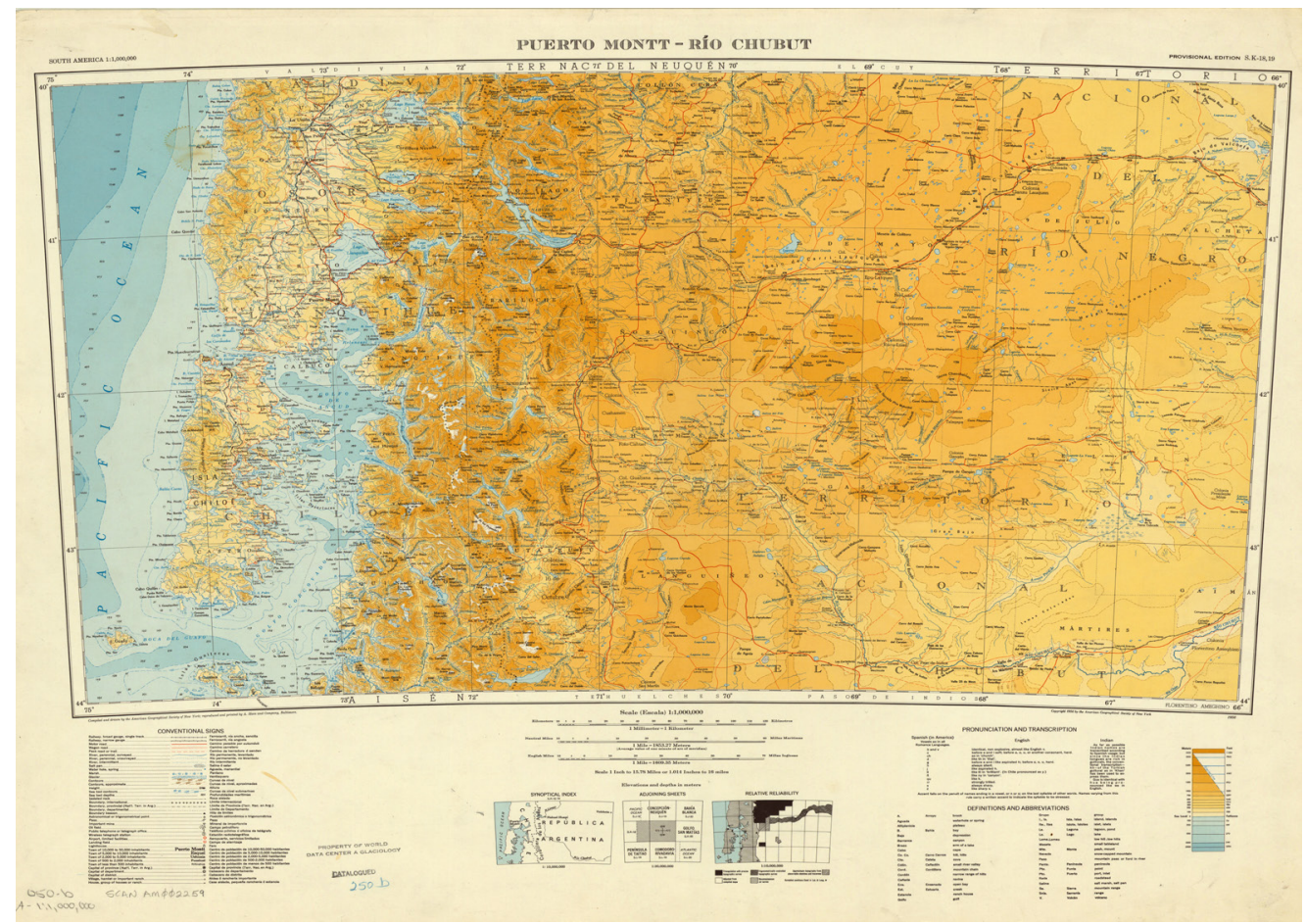

Figure 10. "Puerto Montt - Río Chubut." SK 18-19 (AGS 1956). Teniendo en cuenta que esta hoja reúne varias celdas de la grilla original del MMM, en nombre combina dos topónimos: uno (Puerto Montt) en territorio chileno y otro (Río Chubut) en territorio argentino. 


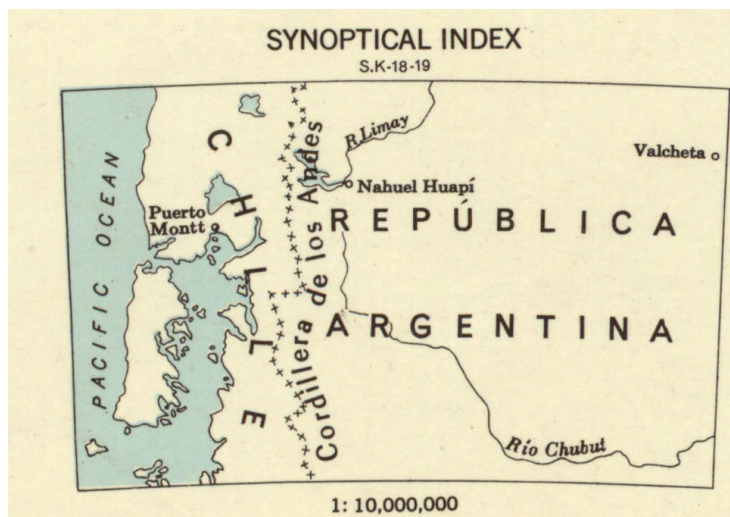

$1: 10,000,000$

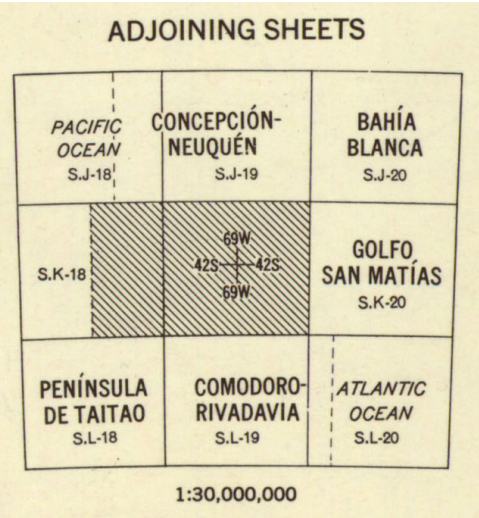

Figure 11. Detalle de figura 10 "Puerto Montt - Río Chubut." SK 18 $\square 19$ (AGS 1956). El índice sinóptico muestra el límite internacional entre Chile y Argentina. El esquema de las hojas representa la compresión de las hojas 18 y 19 para maximizar el uso del espacio cartográfico y reducir la cantidad las hojas impresas.

Como se aprecia en el diagrama que acompaña la hoja (Figura 11), se trataba de incluir en la K19 el pequeño fragmento de tierras que debía aparecer en la hoja adyacente, dado que la hoja S19 estaba en su mayoría cubierta por agua y, desde la formulación inicial del proyecto, se había optado por eliminar la representación de las superficies oceánicas.

Además, el cambio de título se ajusta a dar predominancia a las áreas efectivamente relevadas topográficamente. Ya el criterio no pasa por el accidente geográfico más importante o el poblado más significativo (como sugería el reglamento original) sino por un criterio estrictamente cartográfico que, incluso, habilita a trascender las fronteras nacionales (algo inadmisible en la cartografía nacional y nacionalista).

En cambio, como vimos en la figura 4, la hoja de Comodoro Rivadavia que publicó el IGM se permitió trascender el límite del cuadro de la hoja para no excluir una pequeña porción de territorio argentino (sin una actitud equivalente a los territorios chilenos, es decir, sin incluir los territorios chilenos correspondientes a la misma línea de coordenadas). De este modo, los mapas argentinos no permitieron que ese trocito aparezca en las hojas chilenas y tampoco aceptaron publicar una hoja entera en la que la mayor parte del territorio fuera chileno.

El territorio cartográfico ya se había vuelto un terreno tan disputado como el territorio geográfico.

\section{Conclusiones: Narrar la geografía y cartografiarla siempre tiene un punto de vista}

Los mapas, que se han arrogado la capacidad de representar objetivamente el terreno (o, peor aún, la realidad) son una forma de inscribir ciertos discursos sobre la geografía y el territorio.

Ante el interés generalizado y colectivamente asumido acerca de la importancia de contar con una mapa homogéneo de toda la superficie terrestre, las prácticas institucionales 
concretas que le dieron encarnadura a tal proyecto dejan al desnudo el tipo de objetividad y subjetividad que implican el recorte territorial de cada hoja, los títulos escogidos, los colores seleccionados y la información cartografiada.

Lejos de ser una práctica aséptica, el compromiso institucional de quienes participaron de la confección del mapa al millonésimo lleva a pensar sobre la importancia del punto de vista, del compromiso nacionalista y de la categorización de la información representada que ha definido las prácticas que le dieron existencia a unas aparentemente inocentes hojas topográficas.

Los mapas no representan una realidad. Los proyectos cartográficos no fueron meros emprendimientos científicos. Aunque a menudo se lo conceptualice desde sus características técnicas, incluso en este contexto el mapa, en palabras de Deleuze y Guattari (2002: 17) es un dispositivo:

abierto, conectable en todas sus dimensiones, desmontable, alterable, susceptible de recibir constantemente modificaciones. Puede ser roto, alterado, adaptarse a distintos montajes, iniciado por un individuo, un grupo, una formación social. Puede dibujarse en una pared, concebirse como una obra de arte, construirse como una acción política o como una meditación [...] Contrariamente al calco, que siempre vuelve 'a lo mismo', un mapa tiene múltiples entradas. Un mapa es un asunto de performance, mientras que el calco siempre remite a una supuesta compétanse.

Provocativamente, en el epígrafe que abre este artículo, hicimos decir a Karl Schlögel que las fronteras debieron capitular ante la realidad. Con buen tino, el sociólogo alemán intentaba desnudar la artificialidad del trazo de límites y los conflictos que eso ha entrañado en distintos niveles de la vida social. Pero llegados a este punto del artículo, sabemos que las múltiples realidades obligaron a los mapas a capitular tanto como los mapas hicieron que las realidades capitularan ante la invención de nuevas realidades que imponían con su lenguaje y autoridad científicos.

Las tensiones entre el programa científico idealistamente universalista y los intereses de los estados nacionales involucrados generó geografías insospechadas, disputadas pasivamente con topónimos, recortes y colores.

Las acotadas coyunturas analizadas en este artículo nos acercan a los conflictos intrínsecos a las formas de crear geografías nacionales. Lejos de ser excepciones son expresiones singulares de una problemática común que atraviesa las prácticas políticas y científicas inherentes a los procesos de escritura de una narrativa geográfica, ya sea de naturaleza texto o gráfica. Toda geografía se escribe y se reescribe. Por eso resulta tan importante entender qué es lo que esa geografía describe como entender por qué esa geografía es escrita en esos términos. ¿Qué hacer con las contradicciones entre las diferentes formas de narrar y cartografiar las geografías? Hasta ahora, se ha preferido ignorarlas, reconciliarlas, justificarlas. Las narrativas nacionales han disfrazado sus voluntades nacionalistas para imponerse como discursos hegemónicos, monolíticos y casi mesiánicos ¿No es momento de revisar esas lagunas, esas variaciones, esas diferencias y esas contradicciones para interrogarnos críticamente sobre las imágenes que le dan visualidad a nuestras geografías? 


\section{Notas}

${ }^{1}$ Este artículo forma parte del proyecto de investigación "Looking at Ourselves through Others' Eyes: Foreign Maps and International Networks in Argentinean Cartographical Institutions and Early Argentinean Maps, 1853-1955" desarrollado en la biblioteca de la American Geographical Society - University of Wisconsin (Milwaukee) con el apoyo de una beca del McColl Research Program (2009) y durante una estancia de investigación en University of Wisconsin-Madison con el apoyo de una beca David Woodward Memorial (2010). Este artículo se ha beneficiado también del trabajo realizado en el Équipe d'Épistémologie et Histoire de la Géographie - CNRS Paris 1. EHGO/UMR Géographie-cités en el marco del Programa de Becas de Investigación Postdoctoral HERMES (Fondation Maison des Sciences de l'Homme, MAE/ CNRS/ MESR, 20092010).

${ }^{2}$ El proyecto del Mapa de la América Hispánica se desarrolló entre 1920 y 1945. En líneas generales, se plegó a los requerimientos del proyecto del mapa del mundo al millonésimo (adoptó la misma escala, la misma proyección y la misma simbología). Dio como resultado 107 hojas, de $4^{\circ}$ de latitud y $6^{\circ}$ de longitud. Sobre su precisión y los métodos correctivos que se aplicaron para reducir el margen de error, véase (Pearson y Heffernan 2008; 2014). En particular, véase AGS, 1933.

3 Sobre los emprendimientos de las oficinas cartográficas estatales en la Europa decimonónica, véase (Thrower 1972).

4 "There is no need to recapitulate the slow history of this project. Every two or three years its principles were discussed, and resolutions in favour of it were passed-resolutions which had no effect because they bound no one. At last, at the Geneva Congress of 1908, an incident occurred which might have had great consequences. It is said that a member of our Council and our lately retired Secretary spent an afternoon on a Lake of Geneva steamer in company with the originator of the scheme, and that there the plot was hatched which led in the following year to the calling by the British Government of an official Conference, to which delegates were invited from all the Powers represented by Ambassadors at the Court of St. James" (Hinks 1915: 27).

5 “'La question de l'élaboration d'une carte de la Terre à l'échelle de $1: 1.000 .000$ fut un des principaux sujets de délibération du V Congrès international des sciences géographiques réuni à Berne en 1891 (...). Comme une discussion au sein du Congrès n'aurait donné aucun résultat, tout l'affaire fut confiée à une commission préconsultative, chargée de présenter au Congrès, dans sa séance de clôture, les conclusions auxquelles elle serait arrivée. (...). [Le Congrès de Berne] institue dans ce but une commission composée de savants de diverses nationalités, qui sollicitera les États de faciliter la réalisation de l'œuvre (International Geographical Congress 1896: 3)

${ }^{6}$ Este sistema fue definido como la 1: 10.000 .000 partes de la circunferencia de la Tierra 
desde el Polo Norte hasta el Ecuador pasando por París. En un primer momento quedó estandarizado con una barra de platino y, más tarde, con una aleación de platino iridiado equivalente a 1.093.613 yardas, expresándose en la actualidad en longitudes de onda del átomo de criptón-86.

7 "It is felt that the issue of Provisional Editions of the Carte du Monde tends to obscure the object of the Map. This object is the production of sheets on the same projection and scale and similar in appearance, by every country, so that eventually the world will be covered by a uniform Map. The differences between the Provisional Sheets and those conforming to the 1913 Resolutions are generally in the showing of the ground formations. In other words the numbering and layering of the countries is altered to suit local conditions. This is to be regretted as in many cases there would apparently have been no difficulty in adhering to the Paris Resolutions" (Bureau Central 1926, 5).

${ }^{8}$ El detalle de las hojas es: S.M-18; S.F-G-H-I-J-K-L-M-N-19; S.F-G-H-I-J-K-N-20; S.J21 (Bureau Central 1921: 26).

${ }^{9}$ Estas hojas eran Iguazú, Asunción, Pilcomayo, Corrientes, Posadas, Misiones, Goya, Paso de los Libres, Entre Ríos Norte y Sur, M. Caseros, Buenos Aires, La Plata, Azul, Mar del Plata, Gral. Alvarado, Tres Arroyos, N. Huapi, Aluminé, Neuquén, A. Mahuida, San Rafael Oeste, San Rafael, Mendoza Oeste, Mendoza, San Juan Oeste. Las hojas de Bahía Blanca, San Juan, Chilecito, Los Andes, Salta, La Quiaca, S. de Atacama y Tarija estaban en trabajo de recopilación (IGM 1926: 162).

${ }^{10}$ Por ejemplo, cuando el Instituto Geográfico de Madrid recibió el encargo de ocuparse de la confección de las hojas al millonésimo, "se acordó suspender la construcción del Mapa 1:1.000.000 y dedicar todos los esfuerzos a la rápida terminación del mapa 1:500.00, puesto que formado éste, la publicación del internacional es cosa breve" (Galvis 1926: 8). Por cierto, la cartografía a gran escala quedaba bajo la esfera de la Inspección General de Cartografía dependiente del Estado Mayor.

${ }^{11}$ Incluso en trabajos anteriores hemos adoptado esa perspectiva. Véase Rieznik y Lois 2011.

${ }^{12}$ Por ejemplo, algunas de esas bases fueron Melchior, Decepción, Brown, Esperanza y Cámara.

${ }^{13}$ Esa jurisdicción quedó definitivamente incluida en la estructura administrativa de la información censal (Romero et al. 2004: 83).

${ }^{14}$ Dodds (2000: 164) comenta este viraje de Pastore citando otro texto de Escudé publicado en 1992. 


\section{Bibliografía}

AGS (American Geographical Society). 1933. A catalogue of Maps of Hispanic America. Volume IV: Maps of the Argentine Republic, Chili and Uruguay. New York: American Geographical Society, Publication n. 3 .

AGS (American Geographical Society). 1946. The Map of Hispanic America on the Scale of $1: 1.000 .000$. Geographical Review 36(1): 28.

Bureau Central. Rapport annuel. 1921, 1926, 1928, 1929, 1934.

Cosgrove, D. 2001. Apollo's Eye: A Cartographic Genealogy of the Earth in Western Imagination. Baltimore: The Johns Hopkins University Press.

Crone, G. R. 1966. Historia de los mapas. México-Buenos Aires: Fondo de Cultura Económica.

Dagnino Pastore, L. 1939; 1940; 1944; 1946. Geografía IV año. Buenos Aires: Ediciones Crespillo.

Deleuze, G. and Guattari, F. 2002[1980]. Mil mesetas: capitalismo y esquizofrenia. Valencia: Pre-Textos.

Dodds, K. 2000. "Geopolitics and the Geographical Imagination of Argentina." In Geopolitical Traditions: A Century of Geopolitical Thought, K. Dodds y D. Atkinson (eds.), pp. 150-184. London: Routledge.

Galvis, J. 1926. El mapa internacional en escala 1:1.000.000 y los trabajos en preparación en el Instituto Geográfico. Boletin de la Real Sociedad Geográfica LXVI, pp. 125-130. Madrid: Real Sociedad Geográfica.

Hinks, A. 1915. The Map on the Scale 1:1,000,000, Compiled at the Royal Geographical Society under the Direction of the General Staff , 1914-1915. The Geographical Journal Blackwell Publishing on behalf of The Royal Geographical Society (with the Institute of British Geographers): 24-50.

Hollman, V. y Lois, C. 2011. Imaginarios geográficos y cultura visual peronista: las imágenes geográficas en la revista Billiken (1945-1955). Geografia em questao 4(2): 239-269.

IGM (Instituto Geográfico Militar, Argentina). 1912, 1913, 1926, 1956, Anuario. Buenos Aires: Instituto Geográfico Militar.

International Map Committee. 1910. Resolutions and Proceedings of the International Map Committee assembled in London, November 1909. London: Printed by Harrison \& Sons. 
International Geographical Congress. 1896. Report of the Sixth International Geographical Congress. Held in London, 1895. With maps and illustrations. Edited by the Secretaries. 1896, London: John Murray, Albemarle Street. Berlin: Dietrich Reimer (Hoefer \& Vohsen), Paris: Hachette et Cie.

Mazzitelli Mastricchio, M. 2008. Imaginar, medir, representar y reproducir el territorio. Una historia de las prácticas y políticas cartográficas del Estado argentino 1904 -1941. Tesis de Licenciatura en Geografía, Facultad de Filosofía y Letras de la Universidad de Buenos Aires.

Pearson, A. y Heffernan, M. 2008. Pan-Regional Mapping: The Contribution of the International Map of the World and the AGS Map of Hispanic America to Global Mapping. Paper presented at the ICA Commission on the History of Cartography, International Cartographic Association (ICA-ACI) Symposium on Shifting Boundaries: Cartography in the $19^{\text {th }}$ and $20^{\text {th }}$ centuries, Portsmouth University, Portsmouth, United Kingdom, 10-12 September 2008.

Pearson, A., Taylor, F., Kline, K. y Heffernan, M. 2006. Cartographical Ideals and Geopolitical Realities: International Maps of the World from the 1890s to the Present. The Canadian Geographer / Le Géographe canadien 50(2): 149-176.

Platt Raye, R. 1927. The Millionth Map of Hispanic America. The Geographical Review 17(2): 301-308.

Rieznik, M. y Lois C. 2011. En el "glorioso sendero de la ciencia universal": La Carte Inernationale du Monde $1: 1.000 .000$, la Carte du Ciel y las prácticas de representación del territorio argentino. 1890-1920. Llull. No 34. 121-160. Zaragoza: Sociedad Española de Historia de las Ciencias y de las Técnicas.

Romero, L. A. et al. 2004. La Argentina en la escuela. La idea de nación en los textos escolares. Buenos Aires: Siglo XXI Editores.

Schlögel, K. 2007. En el espacio leemos el tiempo. Barcelona: Siruela.

Thrower, N. 1972. Maps and Civilization. Cartography in Culture and Society. Chicago: University of Chicago Press, Chicago.

Union Géographique Internationale. 1934. Travaux topographiques et cartographiques. Raports présentés à l'occasion du congrès International de Géographie à Varsovie en Août 1934. Varsovia. 